Karina Martinez

GAGLIARDO ${ }^{1}$

Antonio Augusto Coppi

Maciel RIBEIRO ${ }^{1}$

Correspondência para:

ANTONIO AUGUSTO COPPI MACIEL RIBEIRO

Departamento de Cirurgia

Faculdade de Medina Veterinária e

Zootecnia

Universidade de São Paulo.

Av: Prof. Dr. Orlando Marques de Paiva, 87

05508-000 - São Paulo - SP

guto@usp.br

Recebido para publicação: 12/02/2004

Aprovado para publicação: 01/06/2005

\title{
Estudo morfométrico dos neurônios do gânglio mesentérico caudal de cães durante $o$ desenvolvimento pós-natal (maturação e envelhecimento)
}

1 - Departamento de Cirurgia da Faculdade de Medicina Veterinária e Zootecnia da Universidade de São Paulo, São Paulo - SP

\section{Resumo}

O envelhecimento é caracterizado por um progressivo declínio na função neuronal envolvendo tanto o sistema nervoso central como o periférico. $\mathrm{O}$ aumento da idade é verificado por alterações no número e no tamanho do neurônios. Contudo, estes dados são controversos e pouco conhecidos nos gânglios periféricos. Desta forma, o presente estudo teve como objetivo estudar o gânglio mesentérico caudal (GMC) de cães em dois períodos distintos do desenvolvimento (maturação e envelhecimento), a procura de alterações morfométricas nos neurônios. A importância do GMC esta ligada à inervação simpática do intestino grosso, esfíncter anal interno e parcialmente o aparelho urogenital. Para o estudo, foram utilizados nove cães domésticos sem raça definida e machos, divididos em três grupos etários com idades bem definidas (1-2 meses, 1-3 anos e 5-10 anos). Os gânglios foram processados para o estudo da microscopia e luz e as análises morfométricas (área seccional do neurônio e do núcleo) foram realizadas por meio do software de análise morfométrica KS $400 \mathrm{ZEISS}^{\circledR}$. O aumento da idade foi caracterizado por um aumento no tamanho do neurônio e do núcleo. Quanto a relação núcleocitoplasma, esta diminuiu com o aumento da idade.

\section{Introdução}

O envelhecimento, como parte do processo de desenvolvimento, é um evento esperado e normal em todas as espécies animais. Nos mamíferos, a senescência está associada a alterações nas funções fisiológicas e a uma maior suscetibilidade ao aparecimento de doenças degenerativas. Está claro que os prejuízos celulares e fisiológicos que ocorrem com a progressão da idade são resultados de uma interação de vários fatores, podendo dizer que a idade é um fenômeno multifacetado $^{1}$.

No sistema nervoso, a progressão da idade é verificada por um declínio funcional que envolve tanto o sistema nervoso central como o periférico. As alterações freqüentemente relacionadas são a perda e a atrofia neuronal, embora tal afirmação é discutível, pois são verificadas diferenças entre as diversas regiões do sistema nervoso e entre as espécies ${ }^{23}$.

Os efeitos da idade nos gânglios simpáticos pré-vertebrais são pouco conhecidos, embora nos últimos 20 anos estes gânglios têm sido estudados exaustivamente com o auxílio de técnicas farmacológicas, eletrofisiológicas, imunohistoquímicas e bioquímicas ${ }^{4}$; sendo considerados os melhores modelos para estudar e possivelmente solucionar problemas pertinentes ao trato gastrointestinal ${ }^{5}$, uma vez que controlam importantes funções como secreção e absorção de substâncias na parede intestinal, fluxo sanguíneo, participam em arcos reflexos ${ }^{6}$ mesmo com a descentralização do gânglio ${ }^{5,7,8,9}$. 
As alterações degenerativas relacionadas com o envelhecimento nos gânglios simpáticos muitas vezes estão relacionadas apenas a um aumento no depósito de pigmentos como lipofucsina e neuromelanina no interior dos neurônios ${ }^{10,11}$. Ainda, as alterações na arborização dendrítica e axonal, freqüente-mente correlacionadas com a senilidade, não são provocadas por efeitos diretos da mesma, e sim secundárias às mudanças que ocorrem nos órgãos alvos $^{12}$, pois com a progressão da idade pode ocorrer diminuição ou aumento de alguns fatores neutróficos liberados por estes órgãos ${ }^{13,14,15}$.

A atrofia neuronal, por muito tempo correlacionada com a senilidade, pode ser vista em determinados períodos da vida ${ }^{2}$. Paradoxalmente, uma hipertrofia neuronal também pode ser verificada na senescencia, ocorrendo esta paralelamente com a diminuição no número de neurônios ou estando relacionada a um alargamento do corpo celular devido aos depósitos de pigmentos ${ }^{2,16}$.

Desta forma, devido à falta de dados morfométricos sobre os componentes celulares dos gânglios simpáticos prévertebrais nas diferentes etapas do desenvolvimento em grandes mamíferos, e ainda a grande importância funcional do gânglio mesentérico caudal (GMC) na inervação do trato gastrointestinal (inervação simpática do cólon e esfíncter anal interno) e parcialmente do aparelho urogenital, este estudo teve por objetivo investigar possíveis alterações morfométricas dos neurônios encontrados no GMC de cães em dois períodos distintos do desenvolvimento: maturação e envelhecimento.

\section{Materiais e Métodos}

Foram coletados nove gânglios mesentéricos caudais (GMC) provenientes de nove cães domésticos (Canis familiaris), sem raça definida (SRD) e machos, oriundos do Hospital Veterinário da Faculdade de Medicina Veterinária e Zootecnia da
Universidade de São Paulo (HOVETFMVZ-USP). Os animais (e seus respectivos gânglios coletados) foram separados em grupos etários bem diferenciados, visando elucidar as possíveis alterações decorrentes do desenvolvimento, isto é, da maturação e envelhecimento. Os animais considerados nesta pesquisa não apresentavam histórico ou sinais clínicos compatíveis com qualquer neuropatia.

Grupo I (filhotes) - três cães com idades entre 1 - 2 meses $(0,15-0,18 \mathrm{Kg})$. Grupo II (adultos) - três cães com idades entre $1-3$ anos $(13-18 \mathrm{Kg})$.

Grupo III (senis) - três cães com idades entre 5 - 10 anos $(17-23 \mathrm{Kg})$.

Lavagem do sistema circulatório e fixação do gânglio por meio de perfusão

Imediatamente após o óbito dos animais no HOVET-FMVZ-USP, a cavidade abdominal foi exposta através de uma incisão na linha alba (celiotomia préretroumbilical) visando a localização dos principais vasos arteriais e venosos do abdome. A aorta abdominal foi canalizada próximo à emergência da artéria mesentérica caudal e, posteriormente, a veia cava caudal foi seccionada. Uma solução contendo solução salina tamponada fosfatada (PBS) $\left(\right.$ Sigma $\left.^{\circledR}\right)$ a 0,1 M e pH 7.4 e heparina a $2 \%\left(\right.$ Roche $\left.^{\circledR}\right)$ foi perfundida por meio da aorta abdominal, possibilitando a lavagem dos sistemas arterial e venoso. Em seguida, a solução fixadora de Karnovsky modificada, constituída por glutaraldeído 5\% $\left(\right.$ Merck $\left.^{\mathbb{R}}\right)$ e formoldeido a $1 \%\left(\right.$ Sigma $\left.^{\circledR}\right)$ em tampão cacodilato de sódio $\left(\mathrm{EMS}^{\circledR}\right)$ a $0,125 \mathrm{M}$ e $\mathrm{pH} 7.4$ foi perfundida nos animais, através do mesmo vaso utilizado para a solução de lavagem.

\section{Processamento do material}

Logo após a perfusão da solução fixadora de Karnovsky modificada, o GMC foi dissecado "in situ" juntamente com suas conecções nervosas (nervos hipogástricos, plexo intermesentérico e nervos esplâncnicos lombares) e removidos. Estes foram imersos 
na mesma solução fixadora utilizada para a perfusão, onde permaneceram durante um período mínimo de 72 horas.

Após, os gânglios foram seccionados e lavados em solução tampão de cacodilato de sódio $\left(\mathrm{EMS}^{\circledR}\right)$ a $0,125 \mathrm{M} \mathrm{e} \mathrm{pH} \mathrm{7,4,} \mathrm{imersos}$ em solução aquosa de tetróxido de ósmio a $2 \%\left(\right.$ EMS $\left.^{\circledR}\right)$, contrastados em blocos com a solução aquosa saturada de acetato de uranila $\left(\right.$ Reagen ${ }^{\circledR}$ ), desidratados em série crescente de etanóis $50 \%$ em 10 minutos, $70 \%$ em 10 minutos, $90 \%$ em 10 minutos e $100 \%$ em 20 minutos) e óxido de propileno $\left(\mathrm{EMS}^{\circledR}\right)$. Depois destas etapas, as amostras foram embebidas com uma solução de óxido de propileno $\left(\mathrm{EMS}^{\circledR}\right)$ e resina araldite (502 Polyscience Inc. ${ }^{\circledR}$ ), em constante agitação, sendo em seguida transferidos para resina araldite pura (502 Polyscience Inc. $\left.{ }^{\circledR}\right)$ e levados à estufa $\left(60^{\circ} \mathrm{C}\right)$, permanecendo durante um período mínimo de dois dias.

Todos os blocos provenientes do material processado foram trimados para evidenciar as regiões de interesse e seccionados seriadamente com dois micrometros de espessura, com o auxílio do ultramicrotomo MT-XLÒ equipado com um contador de secções e usando navalha de vidro. A seguir, as secções foram coletadas sobre lâminas e coradas com uma solução de azul de toluidina alcoólica. Posteriormente, foram cobertas com uma gota de araldite (502 Polyscience Inc. ${ }^{\circledR}$ ) e montados sob lamínula.

\section{Estudo morfométrico}

A partir de 30 secções seriadas com dois micrometros de espessura, uma área foi escolhida sistematicamente e aleatoriamente para promover a análise morfométrica. Esta foi delimitada por uma área teste $\left(A_{t}\right)$ constituída por linhas de inclusão e exclusão, sendo considerados apenas os perfis que estavam dentro da área teste e que não tocavam nas linhas de exclusão. Os neurônios contidos nesta área foram numerados individualmente, cada um recebendo um número no qual se repetia nas diferentes secções de análise quando se tratava do mesmo perfil neuronal ${ }^{17,18}$.

As três primeiras e as três últimas secções não foram consideradas para a análise morfométrica, seguindo o princípio do "brick"19 , que é uma derivação do trabalho de Gundersen ${ }^{20}$ aplicado ao plano tridimensional. Desta forma, foram analisadas 24 secções, sendo que os neurônios foram considerados para o cálculo da área seccional do corpo neuronal e área seccional do núcleo, ou ainda para a medida de eixos maior ou menor, nas secções onde seu perfil era máximo.

Os dados morfométricos foram obtidos com o auxílio do Programa para processamento e análise de imagens KS-400 Zeiss ${ }^{\circledR}$, devidamente calibrado com uma régua milimetrada. As imagens foram capturadas com o auxílio do microscópio óptico Axioscópio ZeissÒ (Objetiva 20X) e de uma câmara digital TK $1280 \mathrm{OU} \mathrm{JVC}^{\circledR}$ na qual transferia a imagem para uma tela de computador. Foram mensurados 54 neurônios por gânglio (162 por grupo) e 33 núcleos por gânglio (99 núcleos por grupo), provenientes de três diferentes regiões de cada secção, escolhidas sistematicamente e aleatoriamente. Desta forma, foram analisados um total de 486 neurônios e 297 núcleos nesta pesquisa.

A relação núcleo-citoplasma também foi verificada. Para a obtenção desta, foi calculado primeiramente a área seccional do citoplasma obtida por meio da subtração da área seccional do corpo do neurônio pela área seccional do núcleo. Após, foi feita a relação entre a área do núcleo e a área do citoplasma.

\section{Analise estatística}

A análise estatística dos resultados foi realizada por meio do programa Statistical Analysis System (SAS, 1995). A análise da significância dos resultados morfométricos foi testada usando o procedimento PROC ANOVA para análises de variância e, em caso de detecção de efeitos significativos $(\mathrm{P}<0,05)$, utilizou-se o teste de Tukey para a 
comparação múltipla entre as médias dos diferentes grupos de análise.

\section{Resultados}

\section{Estatística morfométrica descritiva}

A área seccional do neurônio, verificada em 162 neurônios, variou no grupo I de 125,50 - 895,00 $\mu \mathrm{m}^{2}$ (média 435 $\mu \mathrm{m}^{2}$; desvio padrão 117,03 ), no grupo II de 123,00 - 1966,50 $\mu \mathrm{m}^{2}$ (média 980,23 $\mu \mathrm{m}^{2}$; desvio padrão 359,46 ) e no grupo III de 136,50 - 3539,30 $\mu \mathrm{m}^{2}$ (média 1185,80 $\mu \mathrm{m}^{2}$; desvio padrão 569,80). No grupo I, 41\% dos neurônios apresentaram um tamanho entre $400-600 \mu \mathrm{m}^{2}$ e no grupo II e III, $24 \%$ e $22 \%$ dos neurônios, respectivamente, entre $800-1000 \mu \mathrm{m}^{2}$ (Figura 1).

A área seccional do núcleo, verificada em 99 neurônios, variou no grupo I de 63,47 - 198,26 $\mu^{2}$ (média 115,20 $\mu \mathrm{m}^{2}$; desvio padrão 24,67), no grupo II de 71,56 - 297,76 $\mu \mathrm{m}^{2}$ (média 179,56 $\mu \mathrm{m}^{2}$; desvio padrão $41,28)$ e no grupo III de 49,72 - 417,85 $\mu \mathrm{m}^{2}$ (média 187,26 $\mu \mathrm{m}^{2}$; desvio padrão 70,66). No grupo I, 64\% dos núcleos apresentaram um tamanho entre $100-150 \mu^{2}$ e no grupo II e III, $48,5 \%$ e $42,5 \%$, respectivamente, entre $150-200 \mu \mathrm{m}^{2}$ (Figura 2).

A relação núcleo-citoplasma (área do perfil nuclear / área do citoplasma), verificada em 99 neurônios, variou no grupo I de 0,14 - 1,50 (média 0,41; desvio padrão 0,22 ), no grupo II de 0,11 - 1,90 (média 0,23; desvio padrão 0,18 ) e no grupo III de 0,04 - 0,66 (média 0,2; desvio padrão 0,08). No grupo I, 28,3\% dos neurônios apresentaram a relação núcleo-citoplasma na classe de 0,20 - 0,29 e $27,3 \%$ na classe $0,30-0,39$. No grupo II, 49\% na classe 0,20 - 0,29 e $42 \%$ na classe $0,10-0,19$. No grupo III, $56 \%$ na classe 0,10 - 0,19 (Figura 3).

\section{Análise de variância (anova)}

O procedimento ANOVA aplicado nos parâmetros morfométricos teve por objetivo detectar possíveis diferenças entre os grupos etários (filhotes, adultos e senis) e ainda constatar significância ou não destas diferenças. Os resultados foram sumarizados na tabela 1 .

Os resultados referentes a área seccional do neurônio demonstraram diferenças significativas entre todos os grupos etários estudados $(\mathrm{P}<0,01)$, isto é, o grupo I diferiu do II, o grupo I diferiu do III e o grupo II diferiu do III.

$\mathrm{Na}$ análise comparativa da área seccional nuclear e da relação entre núcleocitoplasma entre os grupos II e III os resultados não foram significativos ( $\mathrm{P}>0,05)$. Entretanto, os resultados destas duas variáveis morfométricas diferem significativamente $(\mathrm{P}<0,01)$ quando comparado o grupo I aos demais grupos, isto é, o grupo I com o II e o grupo I com o III.

\section{Discussão e Conclusão}

A escolha da espécie canina foi devido ao fato desta representar um modelo experimental de fácil acesso cujos aspectos de sua biologia são claramente conhecidos.

Devido à necessidade da alta resolução e definição para o estudo morfométrico, foi extremamente importante utilizar fixador por meio de perfusão vascular (técnica de fixação mais eficiente no momento) e resina que não

Tabela 1 - Médias das variáveis morfométricas nos três diferentes grupos etários (São Paulo, 2004)

\begin{tabular}{cccc}
\hline \multirow{2}{*}{ GRUPOS } & \multicolumn{3}{c}{ Médias } \\
\cline { 2 - 4 } & $\begin{array}{c}\text { Área neuronal } \\
\text { seccional }\left(\mu \mathrm{m}^{2}\right)\end{array}$ & $\begin{array}{c}\text { Área nuclear seccional } \\
\left(\mu \mathrm{m}^{2}\right)\end{array}$ & $\begin{array}{c}\text { Relação núcleo- } \\
\text { citoplasma }\end{array}$ \\
\hline I (fillhotes) & $\mathbf{4 3 5 \mathrm { a } ^ { * }}$ & $\mathbf{1 1 5 , 2 \mathrm { a }}$ & $0,41 \mathrm{a}$ \\
II (adultos) & $980,23 \mathrm{~b}$ & $\mathbf{1 7 9 , 5 6 \mathrm { b }}$ & $0,23 \mathrm{~b}$ \\
III (senis) & $1185,8 \mathrm{c}$ & $\mathbf{1 8 7 , 2 6 \mathrm { b }}$ & $0,2 \mathrm{~b}$ \\
\hline
\end{tabular}

* Médias seguidas por letras diferentes na mesma coluna diferem entre si pelo método de Tukey $(\mathrm{P}<0,01)$. 
causassem problemas como a retração do material. Frente a esta questão, a utilização do fixador (solução de Karnovsky modificada) apropriado e a utilização de resina plástica do grupo Epoxi (Resina Araldite) para embeber o material foram requisitos primordiais desta pesquisa. A opção pela resina ao invés da parafina está associada a retração que esta causa, como também relatado por Guillery e Herrup ${ }^{21}$, Gardella et $\mathrm{al}^{22}$. Von Bartheld, ${ }^{23}$. Ainda, a utilização da parafina impossibilitaria a realização de cortes semi-finos necessários para as análises morfométricas.

O tamanho dos neurônios no GMC de cães, nas diferentes faixas etárias, verificado através de sua área seccional, aumentou progressivamente e significativamente com o aumento da idade, tendo sido verificado um aumento de $2,25 \mathrm{x}$ do filhote para o adulto e de $1,2 \mathrm{x}$ do adulto para o senil. Semelhantes resultados foram reportados nos neurônios presentes nos gânglios celíaco mesentérico superior, cervical superior $^{11,24,25}$, nodoso $^{26} \mathrm{e}$ hipogástrico ${ }^{25}$.

O aumento no tamanho do perfil neuronal entre os filhotes e adultos é explicado pela incompleta maturação dos neurônios no início das fases de desenvolvimento, como também relatado por Vega, Calzada e Del Valle ${ }^{3}$ e Masliukov ${ }^{27}$. No

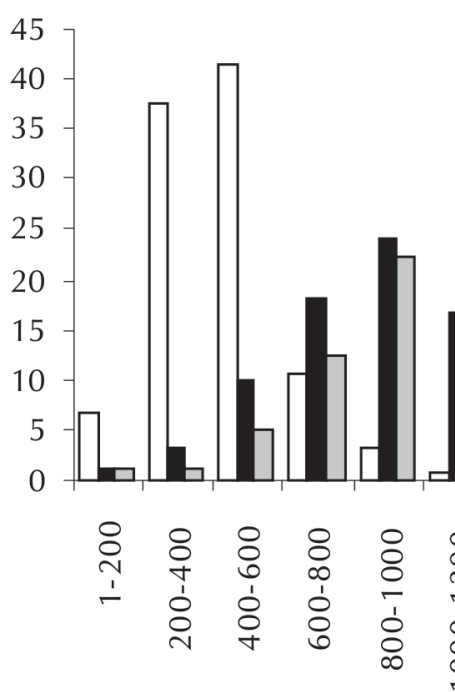

entanto, um aumento significativo no tamanho do perfil neuronal entre um animal adulto e um senil é passível de algumas especulações como: a possibilidade de um alargamento do corpo celular por um aumento no depósito de pigmentos como a lipofucsina ${ }^{2,16}$, ou um aumento do corpo celular pela diminuição da pressão exercida por células vizinhas devido à morte celular ${ }^{24}$, ou um aumento para compensar a perda neuronal com o avanço da idade ${ }^{2,16}$.

Da mesma forma que foi verificado um aumento no tamanho do corpo celular do neurônio com o aumento da idade, foi verificado um aumento no tamanho do núcleo. Porém, o aumento do núcleo foi significativo apenas quando comparado os filhotes com os demais grupos, onde foi encontrado um fator de aumento de 1,56x do filhotes para o adulto e de 1,62x do filhote para o senil. Já do adulto para o senil a mudança no tamanho do núcleo não foi significativa, tendo um fator de aumento de apenas 1,04x. O aumento do núcleo do filhote para o adulto está relacionado com a fase estudada, onde é sabido que nas fases de maturação neuronal é esperado um aumento no volume nuclear ${ }^{28}$, sendo este fato também reportado por Mayhew (1989) nos gânglios da raiz dorsal de ratos de 20 e 120 dias.

Figura 1- Distribuição das classes das áreas seccionais dos neurônios do GMC nos três diferentes grupos etários. 


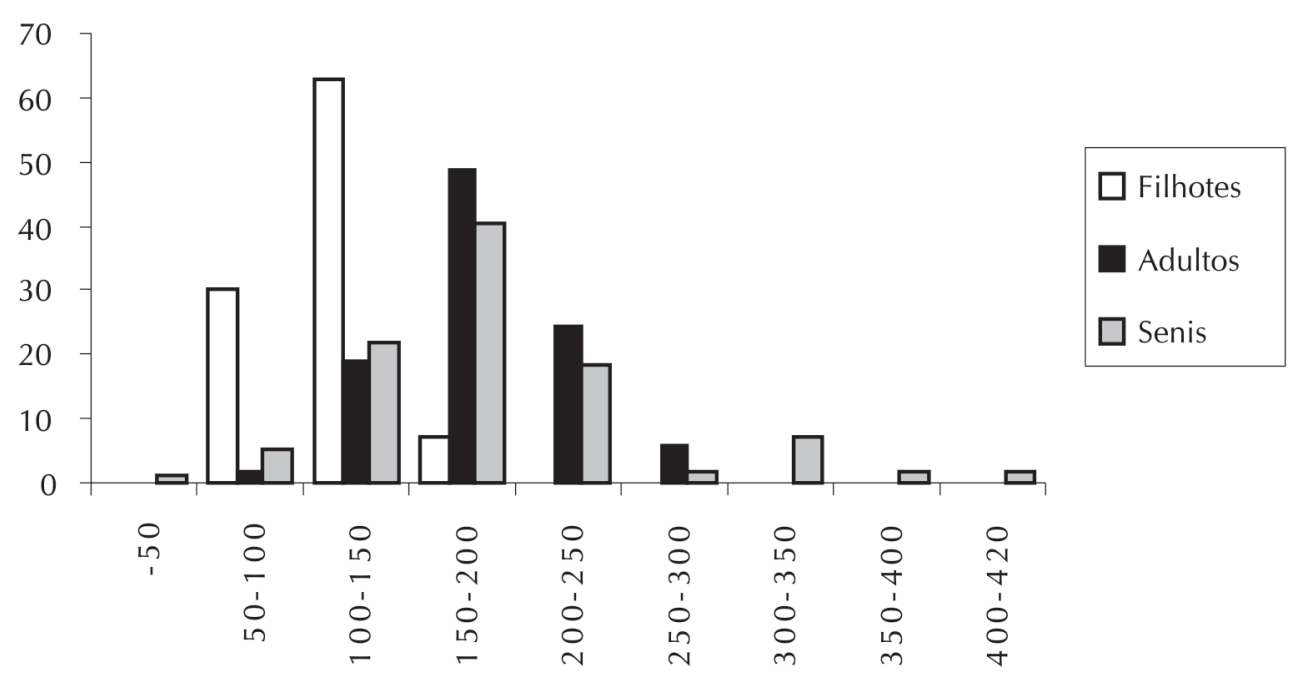

Figura 2 - Distribuição das classes das áreas seccionais dos núcleos do GMC nos três diferentes grupos etários.

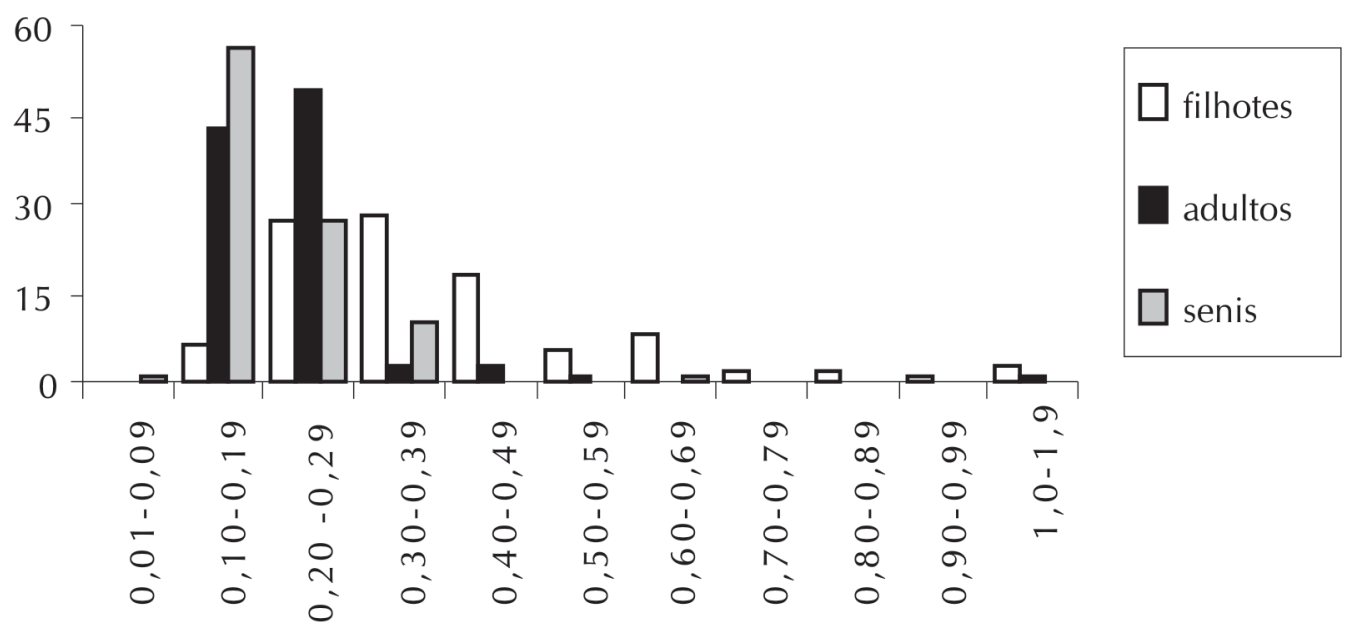

Figuras 3 - Distribuição das classes da relação núcleo-citoplasma no GMC nos três diferentes grupos etários

A relação núcleo-citoplasma nos neurônios do GMC diminuiu com o aumento da idade, da mesma forma dos achados de Ledata et al. ${ }^{29}$. Para ocorrer uma diminuição nesta relação é necessário que a área ocupada pelo citoplasma no filhote seja inferior a área ocupada no adulto e senil, ou que a área ocupada pelo núcleo no filhote seja superior a área ocupada no adulto e senil, ou uma associação das duas hipóteses. Neste trabalho, foi verificado que a área ocupada pelo núcleo aumenta, da mesma forma que aumentou a área ocupada pelo citoplasma. No entanto, embora ambos, núcleo e citoplasma, tenham aumentado, a proporção do aumento do citoplasma foi superior a do núcleo com a progressão da idade.

Os resultados obtidos com esta investigação podem ser úteis no entendimento e tratamento de algumas enteropatias associadas ou não ao envelhecimento. 


\title{
Morphometric study of the neurons in the caudal mesenteric ganglion of the dogs during the post- natal development (maturation and aging)
}

\begin{abstract}
The aging is characterized by a progressive decline of neuronal function that involves both the central and the peripheral nervous system. Aging process is accompanied by changes in the number and size of neurons. However, these data are controvesial and poorly known in the peripheral ganglia. In this way, the present investigation aimed to study the dog's caudal mesenteric ganglion (CMG) in two different phases of aging (maturation and aging), looking for morphometric alterations in the neurons. The importance of the CMG is associated with the innervation of the lower large intestine, internal anal sphincter and partially the urogenital system. To the study, was used nine males, mongrel, domestic dogs, divided into three different well defined aged groups (1-2 months, 1-3 years old, 5-10 years old). The ganglia were processed for light microscopy study and the morphometric analyses were done using morphometric analyses software KS 400 Zeiss ${ }^{\circledR}$. The increase of age was caractherized by an increased in size of neuron and nucleu. Concerning about nucleus-citoplasmic relation, this decrease with the age.
\end{abstract}

\section{Referências}

1 SZWEDA, P. A. et al. Aging, lipofuscin formation, and free radical-mediated inhibition of cellular proteolytic systems. Ageing Research Reviews, v. 2, p. 383-405, 2003.

2 FINCH, C. E. Neuron atrophy during aging: programmed or sporadic? Trends in neurosciences, $\mathrm{v}$. 6, n. 3, p. 104-110, 1993.

3 VEGA, J. A.; CALZADA, B.; DEL VALLE, M. E. Agerelated in the mammalian autonomic and sensory ganglia. In: AMENTA, F. Aging of the autonomic nervous system. London: CRC Press, 1993. p. 31-61.

4 MIOLAN, J.; NIEL, J. The mammalian sympathetic prevertebral ganglia: integrative properties and role in the nervous control of digestive tract motility. Journal of Autonomic Nervous System, v. 58, p. 125-38, 1996.

5 GONELLA, J.; BOUVIER, M.; BLANQUET, F. Extrinsic nervous control of the motility of small and large intestines and related spincters. Physiological Reviews, v. 67, n. 3, p. 902-961, 1987.

6 SZURSZEWSKI, J. H.; KING, B. F. Physiology of prevertebral ganglia in mammals with special reference to inferior mesenteric ganglion. In: SCHULTZ, S. G.; WOOD, J. D.; RAUNER, B. B. Handbook of gastrointestinal physiology. Bethesda: American Physiological Society, 1988. v. 1, section 6, p. 519577.

7 BYWATER, R. A. R. Activity following colonic distension in enteric sensory fibres projecting to the inferior mesenteric ganglion in the guinea-pig. Journal
Key-words:

Aging.

Neurons.

Caudal mesenteric ganglion.

Morphometric.

Dogs. of the Autonomic Nervous System. v. 46, p. 19-26, 1993.

8 LUCKENSMEYER, G. B.; KEAST, J. R. Distribution and morphological characterization of viscerofugal projections from the large intestine to the inferior mesenteric and pelvic ganglia of the male rat. Neuroscience, v. 66, p. 663-671, 1995.

9 LUCKENSMEYER, G. B.; KEAST, J. R. Immunohistochemical characterisation of viscerofugal neurons projecting to the inferior mesenteric and major pelvic ganglia in the male rat. Journal Autonomic Nervous System, v. 61, p. 6-16, 1996.

10 SCHMIDT, R. E; et al. Caractherization of NADPH diaphorase activity in rat sympathetic autonomic gangliaeffect of diabetes and aging. Brain Research, v. 617, p. 343-348,1993a.

11 SCHMIDT, R. E. Neuropathology of human sympathetic autonomic ganglia. Microscopy Research and Technique, v. 35, p. 107-121, 1996.

12 ANDREWS, T. J. Autonomic nervous system as a model of neuronal aging: the role of target tissue and neurotrophic factors. Microscopy Research and Techniques, v. 35, p. 2-19, 1996.

13 BENNETT, M. R.; GIBSON, W. G.; LEMON, G. Neuronal cell death, nerve growth factor and neurotrophic models: 50 years on. Autonomic Neuroscience. Basic and Clinical, v. 95, p. 1-23, 2002.

14 CRUTCHER, K. A. Aging and neuronal plasticity: lessons from a model. Autonomic Neuroscience. Basic and Clinical, v. 96, p. 25-32, 2002. 
15 GAVAZZI, I.; COWEN, T. Can the neurotrophic hypothesis explain degeneration and loss of plasticity in mature and ageing autonomic nerves? Journal of the Autonomic Nervous System, v. 58, p. 1-10, 1996.

16 WARBURTON, A. L.; SANTER, R. M. The hypogastric ant thirteenth thoracic ganglia of the rat: effects of age on the neurons and their extracellular environment. Journal of Anatomy, v. 190, p. 115-124, 1997.

17 GABELLA, G.; BERGGREN, T.; UVELIUS, B. Hypertrophy and reversal of hypertrophy in rat pelvic ganglion neurons. Journal of Neurocytology, v. 21, p. 649-662, 1992.

18 GABELLA, G.; TRIGG, P.; MCPHAIL, H. Quantitative cytology neurons and satellite glial cells in the superior cervical ganglion of the sheep - Relationship with ganglion neuron size. Neurocytology, v. 17, p. 753-769, 1988.

19 HOWARD, $V_{\text {.; }}$ et al. Unbiased estimation of particles density in the tandem scanning reflected light microscope. Journal of Microscopy, v. 138, n. 2, p. 203-212, 1985.

20 GUNDERSEN, H. J. G. Notes on the estimation of the numerical density of arbitrary profiles: edge effect. Journal of microscopy, v. 111, p. 219-223, 1977.

21 GUILLERY, R. W.; HERRUP, K. Quantification without pontification: choosing a method for counting objects in sectioned tissues. The Journal of Comparative Neurology, v. 386, p. 2-7, 1997.

22 GARDELLA, D.;et al. Differential tissue shrinkage and compression in the z-axis: implications for optical dissector counting in vibratome-, plastic- and cryosections. Journal of Neuroscience Methods, v. 124, p. 45-59, 2003

23 VON BARTHELD, C. S. Counting particles in tissue sections: choices of methods and importance of calibration to minize biases. Histology and Histopathology, v. 17, p. 639-648, 2002.

24 BAKER, D. M.; SANTER, R. M. Morphometric studies on pre- and paravertebral sympathetic neurons in the rat: changes with the age. Mechanism of Ageing and Development, v. 42.139-145, 1988.

25 BERGMAN, E.; ULFHAKE, B. Loss of primary sensory neurons in the very old rat: neuron number estimates using the dissector method and confocal optical sectioning. The Journal of Comparative Neurology, v. 396, p. 211-222, 1998.

26 SOLTANPOUR, N.; BAKER, D. M.; SANTER, R. $M$. Neurons and microvessels of the nodose (vagal sensory) ganglion in young adult and aged rats: morphometric and enzyme histochemical studies. Tissues \& Cell, v. 28, p. 593-602, 1996.

27 MASLIUKOV, M. P. Sympathetic neurons of the cat stellate ganglion in postnatal ontogenesis: morphometric analysis. Autonomic Neuroscience, v. 89, p. 48-53, 2001.

28 MCMAHON, S. S.; DOCKERY, P.; MCDERMOTT, K. W. Estimation of nuclear volume as an indicator of maturation of glial precursor cells in the developing rat spinal cord: a stereological approach. Journal of Anatomy., v. 203, p. 339-344, 2003.

29 LEDDA, M.; et al. Decrease in the nucleocytoplasmic volume ratio of rabbit spinal ganglion neurons with age. Neuroscience Letters, v. 286, p. 171174, 2000. 